\title{
The Local Genius Typography as a Source of Idea for Latin-based Typeface Design in Visual Communication Today
}

\author{
Naomi Haswanto \\ Fakultas Seni Rupa dan Desain, Institut Teknologi Bandung, \\ Jalan Ganesa No. 10, Bandung 40132, Indonesia \\ Email: naomidkv@yahoo.co.id
}

\begin{abstract}
During its long history, slowly but sure, Indonesia had accepted the influence of the written language from various nation and civilization. Approximately in the 15th century AD, European brought their language system, Latin, to Indonesia, which had been developed until present time. The usage of Latin alphabet for daily communication in Indonesia has created a disadvantage for the local/ethnic language, especially since the Latin provided an easier writing and speaking system. Latin uses alphabet system in which one sound represents one letter: A, B, C, etc. In contrast, the ethnic language uses syllable system in which one sound could consist of more than one letter ( $a, b a, t a, k a$, $n g a, k h a$, etc). The growing of the nation of Indonesia with its various ethnic groups created the need for unification language, a language with a universal system. Furthermore, the alphabet system is easier to be used for various written and spoken language in the world. The richness of ethnic alphabet from Indonesia could become infinite ideas in developing computer typefaces. A typographer could design Latin alphabet with the characteristic of ethnic alphabets by capturing the traditional elements from the letters. These findings could enrich the field of visual communication nowadays.
\end{abstract}

Keywords: current typeface; Latin alphabetic writing system; local/ethnic typography.

\section{$1 \quad$ Introduction}

As an archipelago country which located between two continents and two oceans, Indonesia had been influenced from various culture and civilization for a very long time. The geographic location and the form of topography which different from area to area had made Indonesia rich of various culture and customs. Every ethnic group has their own different custom and language, including different written language (letters). Indonesia also received the influence of written and spoken language from different stages and time span.

The first stage of influence came from India around the first century AD, which brought the Pallawa letters and Sanskrit language. These letters and language then would influence in the formation of various letters in the Indonesian

Received July $5^{\text {th }}, 2010$, Revised October $29^{\text {th }}, 2013$, Accepted for publication November $8^{\text {th }}, 2013$.

Copyright () 2013 Published by LPPM ITB, ISSN: 1978-3078, DOI: 10.5614/itbj.vad.2013.4.2.7 
archipelago (Nusantara), such as Sumatera (Aceh, Batak, Rejang and Lampung), Java, Sunda, Bali and Sulawesi (Bugis, Mandar and Makassar) [1].

The second stage was brought by the Arabs around the 12th, 13th and 14th century who introduced Arabic letters to read the Holy Quran and for spreading the teachings of Islam. The Arabic letter was also used to write the Malay language, known as Arab Jawi or Pegon.

The third stage of influence came with the arrival of European explorers around the 15th century who brought the Latin language system. At the beginning, the Latin was only used on the paper on agreement between the Colonial and local government. The advance of paper usage and the invention of printer helped to expand of the use of Latin language across Nusantara [2].

The use of Latin in daily communication had made the survival of local and ethnic letters becoming harder and harder. The other reasons for these conditions are as follow:

1. The freedom of the use of written and spoken language offered by Latin had made the language easier to use. Ethnic letters were felt not too practical because the use of the syllable system with the adding of diacritic signs while the Latin features one letter represents one sound.

2. Basically, the ethnic letter is used to communicate within the ethnic itself. Through communication with other ethnic, the development of Indonesian language (which rooted from the Malay language), the official use of Indonesian language as the lingua franca and the influence from foreign language had created new vocabularies which are not exist in the vocabulary of the ethnic language. Therefore, the ethnic language could not act as a bridge to communicate in a nation with various ethnic groups.

3. The Latin language has been used all over the world which gave the easiness in adapting various languages for the need of communication.

\section{Discussions}

Various efforts have been done by language and philology experts along with various departments in order to prevent the extinction of the ethnic alphabet. Several of them were the creation of ethnic alphabet in a computerized system such as the digitalization of Batak alphabet by Prof. Uli Kozok and Unicode of the Sunda alphabet by Ministry of National Education of West Java.

The computerized system of ethnic alphabets is mostly used to transliterate ancient scripts so the message could be read and understood by the present generation. Other usage is by implementing those letters as the identity of the 
city, through the street naming using the ethnic alphabet along with the Latin language. This practice could be found in Yogyakarta (through the use of Javanese letters, the Hanacaraka) and Bandung (which applied the Sunda alphabet for street naming).
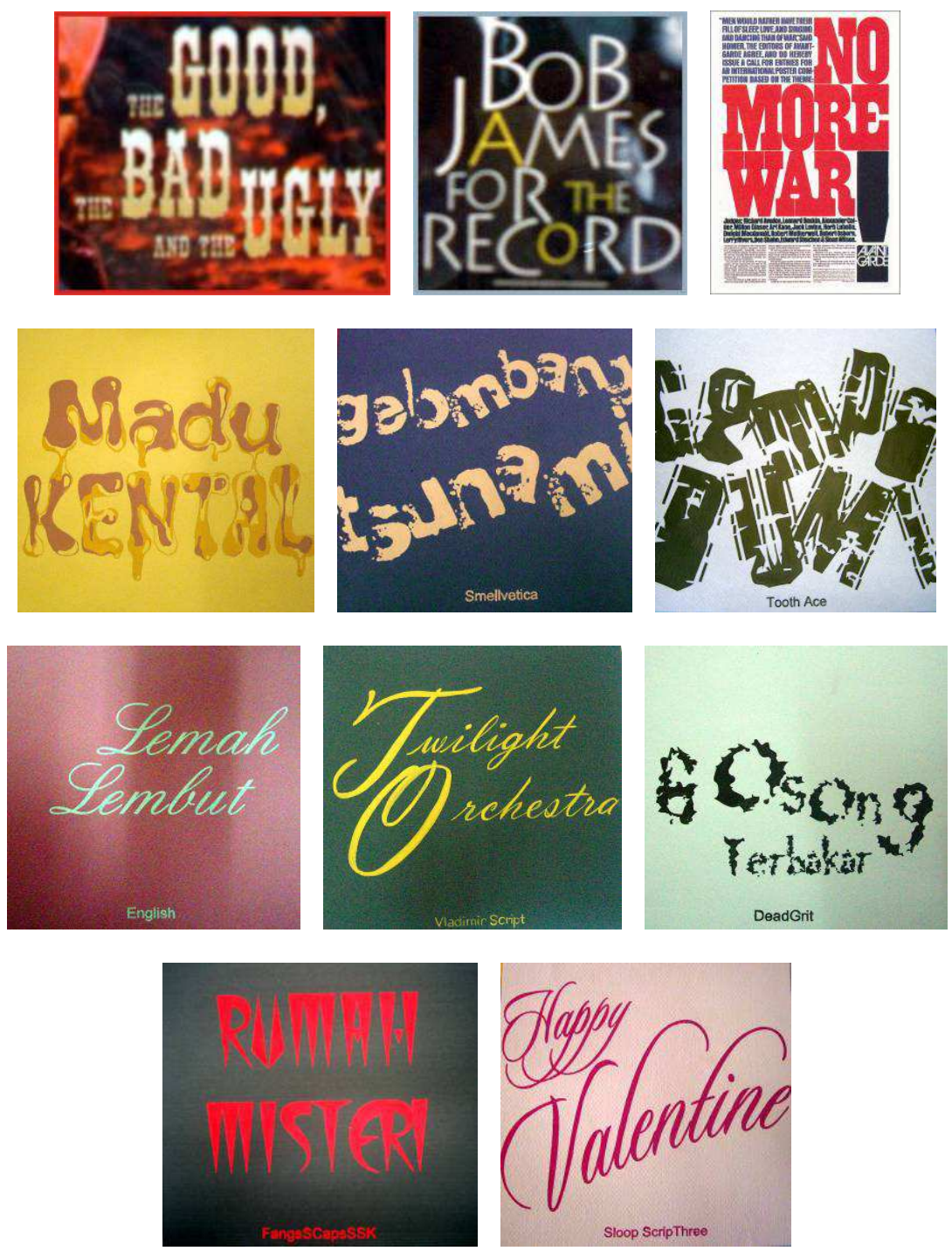

Figure 1 The form of type has various characters emotions that expressed typographically; each symbol representing a specific sound. 
The problems to use the ethnic alphabet also related to the matter of habit. Would we continue to re-study these ethnic language or to change the Latin language system to the ethnic language? The implication is not something that is unrealistic and impossible to achieve since we could witness the use of ethnic alphabet in its fullest in the countries of Thailand, India, China and Japan. In these countries, the ethnic language is used as the main language for communication and it goes hand in hand with the Latin system.

The Latin alphabet which is studied in the field of Typography is not only served as a fonetic symbol to convey messages. Typography, according to the dictionary, is the art or process of printing with type, the root words that make up typography are typo (type) and graph (drawing), so it literally means drawing with type. The very essence of typography is translating the equivalencies of spoken language into printable form. Verbal becomes an equivalent to visual. The integrity of the type's form could create a degree of readability and legibility. Readability and Legibility is central issues in typography because type is created to be read. The form of alphabet has various characters with emotions that could be expressed typographically; each symbol representing a specific sound (see Figure 1 [3-5]).
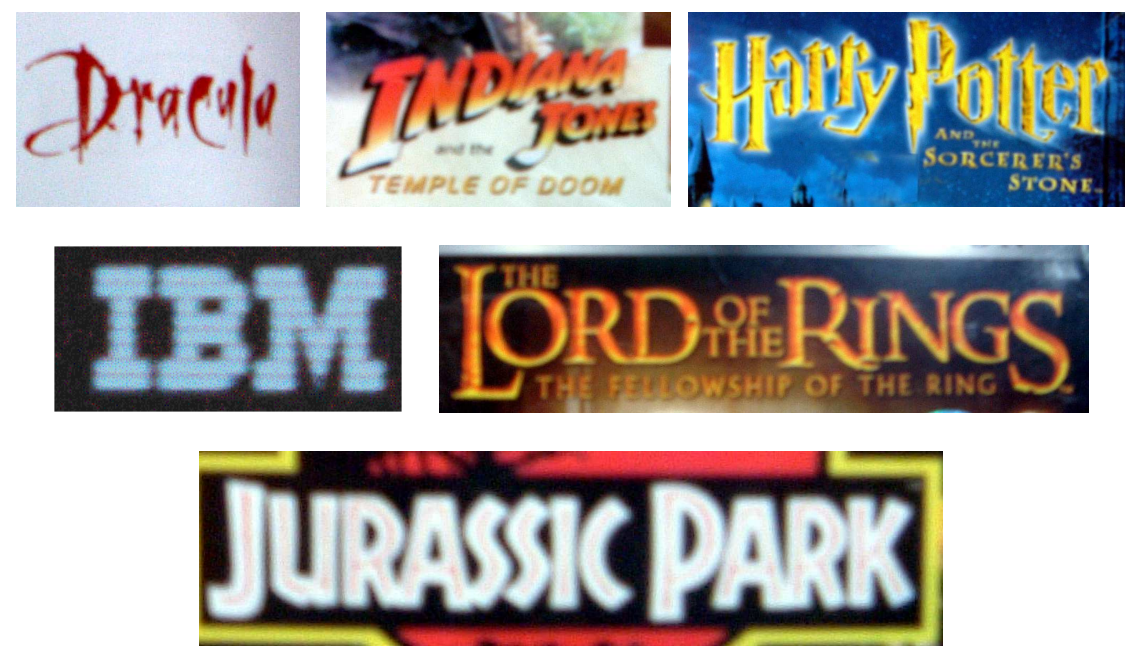

Figure 2 The Title of Film or Corporate have various characters an emotions that expressed typographically; each symbol representing a specific branding.

Typographers can create letters that have more complex meanings which are categorized by family types, style, case, size, weight, bold, regular, slim, italic, condensed, back slanted and so forth. Visual form of the type does not only 
deliver the message and meaning but also the tone of voice and feeling, hierarchy and importance, explanation and clarity (e.g. see Figure 2).

The alphabet also features a distinctive characters in its form and visual. These characters could be used to emphasize particular expression, mood for the visual design (in advertising, websites, Logotype, branding/identity, etc.) in the works from Visual Communication Design field.

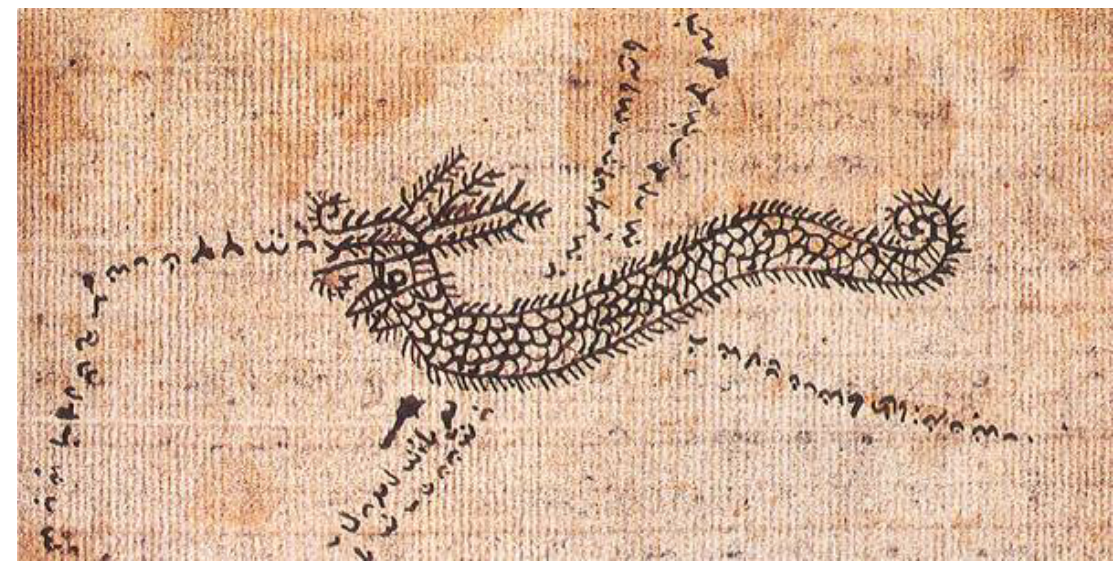

Figure 3 Bugis Typography in letter "Ukiq Sulapaq Eppai".

With its abundance of resources on the ethnic alphabet in Indonesia, the opportunity to create new ideas by collaborating and integrating ethnic letter into Latin alphabet is open widely. Designers and typographers could design new Latin-based alphabet that feature the form and visual that resemble ethnic letters into new typefaces. This study could be developed to create interesting typefaces because each ethnic letters was founded based on geographical condition, local context and local culture, which unique from one another.

In creating new typeface, accuracy and carefulness is a must attitude for typographers that enable them to capture the character identity in local genius typography. With the richness and the flavor of local genius, the ethnic alphabets are unlimited resources. Ethnic alphabets found on various writings, pictures, and signs in the local environment could become a cultural asset of a country. Although most of these ethnic alphabets (also known as vernacular typography) are often ignored because of their 'old' and traditional look, more or less they create a uniqueness which will become local genius in Indonesia (e.g. see Figures 3 and 4). 


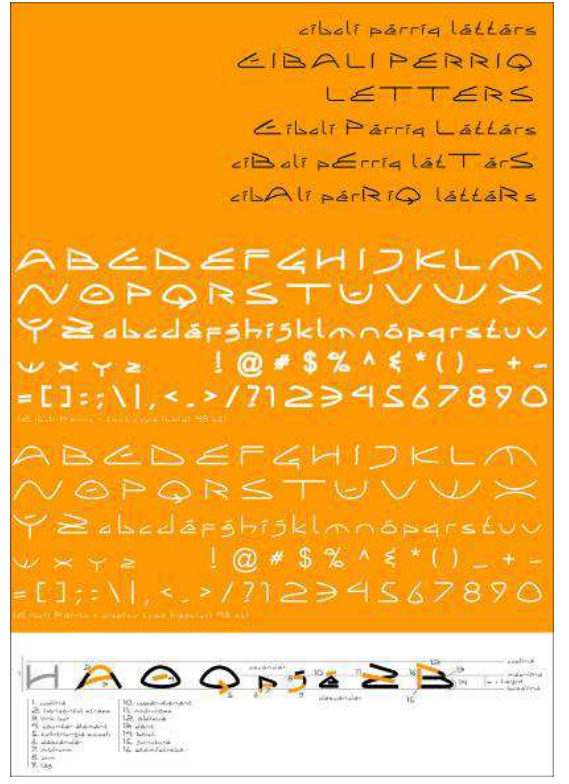

(a)

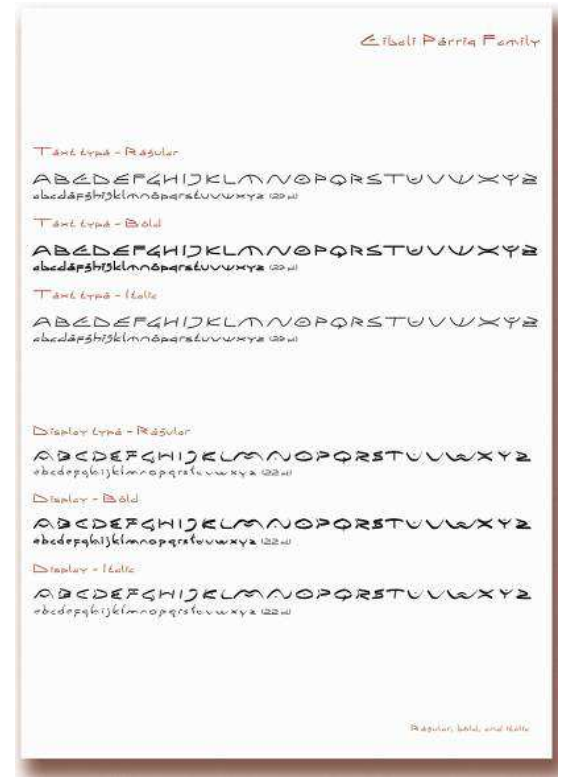

(b)

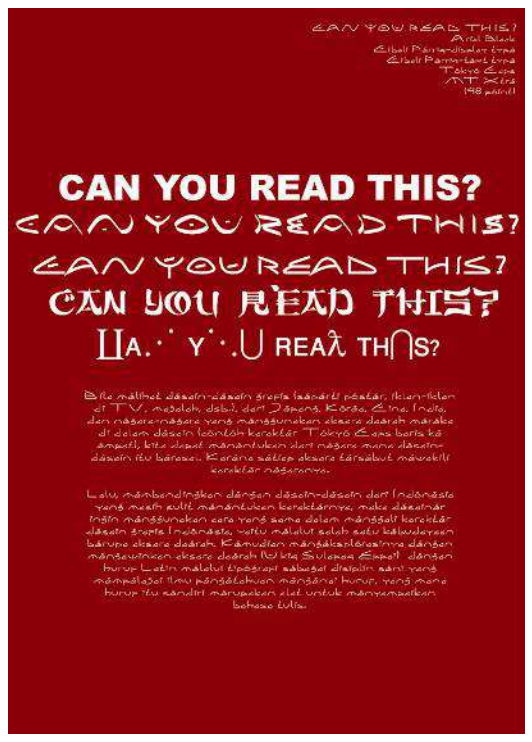

(c)

Figure 4 (a), (b), (c) New typeface "Cibali Periq" creation by Clefiena, base from Bugis Typography in letter "Ukiq Sulapaq Eppai”. 


\section{Conclusion}

From the above case study, it is possible to create different typeface from similar material in different culture in Indonesia. However, this creative process still needs academic review to classify, arrange, and assemble those resources to create a structured and accountable new typeface.

There are various applications/softwares to design, create and publish new font designs (font generating) such as: Macromedia Fontographer, Pyrus Fontmaker, Hight Logic Font Creator and Fontlab Studio. If the design process of creating new fonts is successful, these works would enrich the vocabulary of existing typefaces and could be applied for designing present day's work.

\section{References}

[1] Hardiati, E.S. 2002. Growth of Aksara in Indonesia, Catalogue Exhibition Growth of Aksara in Indonesia, Museum National, Jakarta.

[2] Sunarto, P. 2002. Latin Alphabet in Indonesia, Catalogue Exhibition of Development of Aksara in Indonesia Museum National, Jakarta.

[3] White, A.W. 2005. Thinking in Type, The Practical Philosophy of Typography, Allworth Press, New York.

[4] Clair, K. 1999. A Typographic Workbook, A Primary of to History, Techniques and Artistry, John Wiley \& Sons, Inc., New York.

[5] Sihombing, D. 2001. Typography in Graphic Design, Gramedia Pustaka Utama, Jakarta. 